\title{
Um projeto político-pedagógico de graduação em Fisioterapia pautado em três eixos curriculares
}

\author{
A political-pedagogical project of Physical Therapy's graduation based in \\ three curricular components
}

\author{
Marcos Claudio Signorelli ${ }^{[a]}$, Vera Lucia Israel ${ }^{[b]}$, Clynton Lourenço Corrêa ${ }^{[c]}$, \\ Arlete Ana Motter ${ }^{[\mathrm{d}]}$, Sibele Yoko Mattozo Takeda ${ }^{[\mathrm{e}]}$, Anna Raquel Silveira Gomes ${ }^{[\mathrm{f}]}$
}

[a] Doutorando em Saúde Coletiva pela Universidade Federal de São Paulo (UNIFESP), docente do Curso de Fisioterapia da Universidade Federal do Paraná (UFPR), Matinhos, PR - Brasil, e-mail: signore@ufpr.br

[b] Doutora em Educação Especial pela Universidade Federal de São Carlos (UFSCar), docente do Curso de Fisioterapia da Universidade Federal do Paraná (UFPR), Matinhos, PR - Brasil, e-mail: veral.israel@gmail.com

[c] Doutor em Neurociências pela Universidade Federal do Rio de Janeiro (UFRJ), docente do Curso de Fisioterapia da Universidade Federal do Paraná (UFPR), Matinhos, PR - Brasil, e-mail: clynton@ufpr.br

[d] Doutora em Engenharia de Produção pela Universidade Federal de Santa Catarina (UFSC), docente do Curso de Fisioterapia da Universidade Federal do Paraná (UFPR), Matinhos, PR - Brasil, e-mail: arlete.motter@uol.com.br

[e] Mestre em Fisioterapia pela Universidade Metodista de Piracicaba (Unimep), docente do Curso de Fisioterapia da Universidade Federal do Paraná (UFPR), Matinhos, PR - Brasil, e-mail: betyboopfisio@yahoo.com.br

[f] Doutora em Ciências Fisiológicas pela Universidade Federal de São Carlos (UFSCar), docente do Curso de Fisioterapia da Universidade Federal do Paraná (UFPR), Matinhos, PR - Brasil, e-mail: annaraquelsg@gmail.com

\section{Resumo}

Introdução: O Setor Litoral da Universidade Federal do Paraná (UFPR), com seu Projeto PolíticoPedagógico (PPP) inovador, baseado na Teoria da Complexidade, está finalizando o processo de implantação de sua primeira turma de Fisioterapia. Objetivos: Comentar algumas das bases teóricas que sustentam tal projeto pedagógico, apresentando a experiência da construção coletiva de um PPP pautado em três eixos curriculares. Metodologia: De caráter qualitativo e de cunho teóricoreflexivo. Resultados: A construção do PPP resultou numa organização curricular em três eixos: Fundamentos Teórico-Práticos (FTP), Projetos de Aprendizagem (PA) e Interações Culturais e Humanísticas (ICH). Os FTP (aproximadamente $60 \%$ do currículo) compreendem módulos temáticos elaborados por equipe interdisciplinar de professores, contextualizados com a realidade do mundo do trabalho, aproximando-se dos princípios do Sistema Único de Saúde (SUS) e atendendo às Diretrizes Curriculares Nacionais (DCN). Nos PA, o estudante desenvolve projetos mediados por 
docentes, que envolvem necessariamente a tríade “ensino-pesquisa-extensão”. Esses são imbricados à realidade do litoral paranaense, extensiva e/ou ampliada para outras comunidades. Já as ICH (20\% do currículo) são espaços para a vivência de um diferencial na gênese do fisioterapeuta: uma formação pautada na complexidade do ser humano e na integração deste com o meio, pois são realizadas em conjunto com outros cursos e comunidade. Considerações finais: Nessa trajetória, os estudantes que se desenvolvem pela UFPR já demonstram características diferenciadas, resultantes de práxis generalista, humanista, crítica e reflexiva, como preconizam as DCN. Esperamos que essa vivência proporcione articulação de saberes e práticas, formando profissionais qualificados, cidadãos conscientes e sensibilizados para a coletividade.

Palavras-chave: Ensino. Currículo. Fisioterapia. Educação. Profissão.

\begin{abstract}
Introduction: UFPR Litoral with its innovative PPP (Political-Pedagogical Project), based on Complexity Theory, is finalizing the implementation of its first Physical Therapy graduating group. Objectives: To comment some of the theoretical basis which sustain the project, presenting the experience of PPP's collective construction process, focusing three curricular components. Metodology: Qualitative, with a theoretical-reflexive approach. Results: $P P P^{\prime}$ 's construction resulted in a curricular organization based in three componets: TPF (Theoretical and Practical Fundaments), LP (Learning Projects) and CHI (Cultural and Humanistic Interactions). TPF consists about 60\% of the curriculum, comprehending thematic modules elaborated by interdisciplinary professors team, based on the contextualized situation of the profession reality outside the campus. All contents taught follow Brazillian national curricular guidance and national health system. The PA allows students to develop projects, mediated by professors involving the triad: teaching-research-extension. These are contextualized to the reality of Parana's coastal communities, and also extended or amplified to other communities. The CHI (consisting $20 \%$ of the curriculum) allows the future professionals to experience the complexity of human being and its integration to the surrounding environment, once they share experiences with other graduation courses and communities. Conclusions: Throughout all these processes, UFPR students demonstrate distinguished characteristics, that come from generalist, humanist, critical and reflexive praxis, as recommended by national curricular guidance. So we hope these experiences provide articulation of knowledge and practices, developing qualified professionals and conscious citizens who care for the collectivity.
\end{abstract}

Keywords: Teaching. Curriculum. Physical therapy. Education. Profession.

\title{
Introdução
}

A Educação, como área de conhecimento, vem se ampliando ao longo dos anos. São teorias, experiências, saberes cientificamente construídos que abordam a epistemologia do conhecimento e estratégias de novas metodologias, que instrumentalizam a prática pedagógica. O processo pedagógico da área de Saúde também é discutido, refletido, construído e reconstruído, para atender a demandas educacionais e sociais do mundo contemporâneo.

Nesse cenário, o processo formativo em Fisioterapia vem sendo (re)estudado, (re)discutido, (re) visto e continuamente atualizado, agregando novos conceitos com base no cotidiano entre ensino, pesquisa, extensão, com uma intervenção ampliada na área do conhecimento da profissão de fisioterapia. O trabalho é intenso e extenso: alguns autores se debruçam sobre a teoria, outros sobre a prática, discutindo o ensino em Fisioterapia em diversos espaços, como fóruns e eventos específicos. Merece destaque, particularmente, o Fórum da Associação Brasileira de Ensino em Fisioterapia (ABENFISIO), que se constitui em espaço privilegiado para o intercâmbio de experiências. No entanto, apesar de tanta discussão, os PPP's dos cursos de Fisioterapia da maioria das Instituições de Ensino Superior (IES) parecem perpétuos, intocáveis e distantes de qualquer possibilidade de ação reflexiva que gere transformações. 
Dentre os cursos de Fisioterapia, destaca-se aqui o da UFPR, uma instituição federal que está prestes a comemorar seu primeiro centenário. Ao longo deste quase século de existência, vem desenvolvendo profissionais nas mais diversas áreas, numa formação que tem como prerrogativa a educação pública, gratuita e de qualidade. Entretanto, até meados de 2005, a universidade não oferecia a Graduação em Fisioterapia. A criação do curso ocorreu nesse ano, quando diagnosticada pelos gestores da UFPR a carência de sua oferta em IES Pública no Estado do Paraná. Atentos à predominância dos cursos de Fisioterapia em instituições pagas, e preocupados com o baixo Índice de Desenvolvimento Humano (IDH) no litoral do Paraná, os dirigentes da UFPR decidiram então pela sua criação no Setor Litoral, situado no Balneário Caiobá, município de Matinhos.

Todo o processo de implantação e desenvolvimento do curso foi estrategicamente pensado, construído e (re)avaliado de maneira coletiva. Ele poderia ser mais comodamente oferecido no câmpus sede, em Curitiba, que contabilizava na época sete cursos em IES pagas. Lá, a UFPR também dispunha de certa estrutura na área da Saúde, como laboratórios e dois hospitais universitários: Hospital de Clínicas (HC) e Hospital do Trabalhador (HT). Mas em vez de centralizar mais um curso na capital paranaense, seguindo um modelo hospitalocêntrico, optou-se pela abertura do curso no mais novo câmpus da instituição, no litoral. Esta é uma das regiões menos favorecidas do Estado, social e economicamente. A abertura do então denominado Câmpus Litoral (hoje Setor Litoral) fazia parte de um plano de interiorização do ensino superior público, que mais tarde deu origem a diversas expansões de outras universidades federais e ao Programa de Apoio a Planos de Reestruturação e Expansão das Universidades Federais - REUNI. ${ }^{1}$

Ao longo de quase quatro anos, uma equipe de professores (fisioterapeutas e de outras áreas do conhecimento), em uma abordagem interdisciplinar, vêm aprimorando e consolidando a proposta de implantação do curso. Buscando formação diferenciada para os fisioterapeutas, o PPP é norteado em três eixos curriculares: Fundamentos Teórico-Práticos (FTP), Projetos de Aprendizagem (PA) e Interações Culturais e Humanísticas (ICH). Neste artigo, almejamos fazer um relato dessa experiência, destacando aspectos como a fundamentação teórica que norteia a proposta, até a construção na prática, destacando os principais desafios e êxitos.

\section{Relato da experiência: a construção de um PPP inovador}

O litoral do Paraná é o berço da civilização paranaense e conserva até hoje um vasto patrimônio cultural e natural. A região possui uma população de aproximadamente 300 mil habitantes, que varia muito em função de aspectos sazonais. No verão, ela ultrapassa a casa de um milhão. Nesse período, a região atrai pessoas que desejam passar férias, desfrutando das belezas naturais. A população fixa, por sua vez, vive principalmente da pesca, agricultura e serviços, destacando-se aí os empregos diretos e indiretos relacionados aos portos de Paranaguá e Antonina. Tal sazonalidade influencia diretamente a conjuntura socioeconômica: durante os meses de verão há geração de emprego e renda, principalmente em atividades ligadas ao turismo e ao comércio; já no restante do ano, grande parte da população sobrevive sem trabalho. Isso, como é sabido, pode ocasionar sérios agravos sociais à população, o que se reflete no IDH dos municípios da região, bem inferiores aos da capital do Estado ${ }^{2}$. Essa é, portanto, uma das áreas menos desenvolvidas do Paraná, tanto do prisma econômico quanto do social.

Até meados de 2005, a região não possuía nenhuma universidade, apenas algumas faculdades isoladas, nenhuma das quais oferecia cursos de Fisioterapia ou qualquer outro do campo da Saúde. E haja vista toda a necessidade socioeconômica da região, associada às demandas específicas em Saúde, optou-se pela implantação do curso de Fisioterapia no Câmpus Litoral da UFPR. Assim, a denominada UFPR Litoral veio não somente para oferecer cursos para uma população menos favorecida, e até excluída socialmente, mas, acima de tudo, para ser um agente promotor do desenvolvimento sustentável da região.

\footnotetext{
1 O REUNI foi criado pelo decreto presidencial n. 6.096, de 24 de abril de 2007, e visa a, dentre outras estratégias, ampliar o acesso da população às instituições federais de ensino superior.

2 O IDH dos municípios do litoral do Paraná encontra-se no site www.ampr.org.br.
} 
Partindo dessa premissa, o desafio estava posto: como promover o desenvolvimento local sustentável por meio da implantação de um câmpus universitário? E, mais especificamente, por meio dos cursos oferecidos nesse câmpus?

Tradicionalmente, a universidade pública é um espaço privilegiado, no qual parcela ínfima da população tem a oportunidade de frequentar os cursos de graduação. Por entender que o ensino é dever do Estado e direito de todos, a UFPR teve como desafio a democratização do acesso ao ensino superior para a população desfavorecida nos diferentes âmbitos. Nesse sentido, a instituição vem adotando estratégias de inclusão educacional e social. Uma das ações afirmativas da UFPR é o sistema de cotas no ingresso do vestibular. São oferecidos $20 \%$ do total das vagas para as denominadas cotas sociais, destinadas a quem estudou durante o ensino fundamental e médio integralmente em escolas públicas. Porcentagem idêntica é reservada às cotas de origem étnico-raciais, para candidatos afrodescendentes. Mais recentemente, a instituição aprovou uma vaga por curso destinada a pessoas com deficiências e passou a realizar um vestibular indígena, que permite o acesso deste grupo étnico específico. Além do ingresso por meio do vestibular, a universidade estimula a ocupação de vagas ociosas, oriundas de acadêmicos desistentes, pelo Processo de Ocupação de Vagas Remanescentes (Provar), destinado às transferências (internas e externas), complementação de estudos, reintegração de ex-alunos e aproveitamento de curso superior para pessoas que já possuem diploma e desejam realizar outra graduação.

Entretanto, apenas democratizar o acesso à universidade não era suficiente para superar o desafio colocado. Era preciso repensar as próprias estratégias pedagógicas. O paradigma tradicional de ensino, centrado no conhecimento fragmentado em disciplinas e na figura do professor, detentor do saber e transmissor de conhecimentos; em currículos engessados e focados no tecnicismo das profissões; em departamentos que não dialogam entre si, bem como profissões que não se comunicam, esse modelo vem se demonstrando extremamente ultrapassado. Não caberia nessa região, que apresenta tantas demandas, apenas abrir cursos indiscriminadamente, sem pensar numa concepção político-pedagógica que desse conta de todos esses aspectos. Era preciso que a universidade extrapolasse as barreiras dos seus muros, e que a comunidade universitária deixasse de olhar apenas para dentro de si. Assim, tanto para a implantação do curso de Fisioterapia quanto dos outros cursos da UFPR Litoral, era imprescindível a construção de um PPP que contemplasse todos esses aspectos descritos anteriormente.

Esse novo paradigma emerge principalmente com base em fundamentos teóricos de autores como Paulo Freire, Boaventura de Sousa Santos, Humberto Maturana, Francisco Varela, Edgar Morin, entre outros, em contraponto à visão reducionista e cartesiana que tem pautado a educação e a investigação científica. Este estudo não pretende discutir exaustivamente suas teorias, nem esgotar o assunto. Aqui, apresentaremos sinteticamente as principais contribuições teóricas de alguns autores que alicerçaram a construção do PPP do curso de Fisioterapia da UFPR Litoral, curso esse que tem como particularidades, entre outras: a aprendizagem baseada em trabalho por projetos; os três eixos curriculares anteriormente mencionados (FTP, ICH e PA); a organização das atividades formativas em três fases: 1) conhecer e compreender, 2) compreender e propor e 3 ) propor e agir; e a gestão política, administrativa e pedagógica realizada por uma câmara interdisciplinar de docentes, técnicos e discentes.

Para iluminar o debate, trazemos Humberto Maturana e Francisco Varela, criadores da Teoria da Autopoiese e da Biologia do Conhecer e propositores do pensamento sistêmico e do construtivismo radical. Em síntese, sua teoria e forma de pensar acabam com o antigo dualismo mente-corpo, identificando o processo do viver com o processo cognitivo. Esses autores enfatizam o processo de conhecimento construído a partir das interações (1). Em seus postulados, destaca-se o resgate das emoções, num processo de (re)valorização das mesmas. Essa teoria emerge dentro de uma conjuntura atual que tem escondido as emoções, por ir contra a razão. Maturana coloca o ser humano como um ser vivo em particular e que o amor é a emoção que o sustenta, sendo fundamental na aceitação do outro. Partindo dessa premissa, a equipe atentou para a fragmentação existente em currículos tradicionais, como no caso das disciplinas da área Biológica que não dialogam com as disciplinas das áreas das Ciências Humanas, como Psicologia, Antropologia, Filosofia ou Sociologia. Outro aspecto significante colocado pelos autores é a valorização das emoções. Nesse sentido, refletiu-se sobre o extremo tecnicismo com que as carreiras acadêmicas vêm direcionando a formação, de modo especial na área da Saúde. Esse tecnicismo acentuado muitas vezes deixa de lado os aspectos subjetivos do ser humano, 
fundamentais em profissões que lidam com seres humanos, como no caso da Fisioterapia. Assim, ao longo de todo o curso, compõem o mapa curricular as ICH, que correspondem a 20\% da carga horária. Nesse espaço curricular, estudantes de diferentes cursos da UFPR Litoral participam juntos de atividades, como oficinas, debates, vivências, saídas de campo, práticas, que permitem uma sensibilização para as questões que Maturana e Varela colocam, estimulando a interação e a interprofissionalidade.

Outro elemento importante que fundamentou a estruturação da UFPR Litoral e do curso foi a Teoria da Complexidade, proposta por Edgar Morin. Segundo Morin (2, p. 20), “À primeira vista, a complexidade é um tecido de constituintes heterogêneos inseparavelmente associados: coloca o paradoxo do uno e do múltiplo. A complexidade é efetivamente o tecido de acontecimentos, ações, interações, retroações, determinações, acasos, que constituem o nosso mundo fenomenal. Mas então a complexidade apresenta-se com os traços inquietantes da confusão, do inextricável, da desordem, da ambigüidade, da incerteza... Daí a necessidade, para o conhecimento, de pôr ordem nos fenômenos ao rejeitar a desordem, de afastar o incerto, isto é, de selecionar os elementos de ordem e de certeza, de retirar a ambigüidade, de clarificar, de distinguir, de hierarquizar..."

Morin (2) e Morin e Le Moigne (3) associam a complexidade à noção de imprevisibilidade, incerteza, confusão e desordem, porém, ressaltam a importância da estratégia para fazer frente ao instável e incerto. Associa-se o termo "complexidade", também, à noção de várias partes interconectadas: "não só a parte está no todo, mas também o todo está na parte" (4). Em resumo, a complexidade proposta por Morin se refere a um conjunto de eventos, principalmente aqueles ligados à área científica, que ocorreram no fim do século XIX e que foram sendo debatidos, combatidos e assimilados no decorrer do século XX. Após quase três séculos de determinismo, de racionalismo, de univocidade, de concepção mecânica de mundo e, principalmente, da certeza que se transferia ao experimento científico, tudo isso cai por terra com as descobertas da própria ciência (5-7). Primeiramente, tem-se a revelação de que existem fenômenos que não se consegue explicar. $\mathrm{O}$ próprio ser humano é um deles, o universo também, a vida e a morte, o amor, o ódio (a reaproximação da filosofia e da ciência) (8). Depois, descobre-se que o mundo pode ser um sistema (9), um ecossistema, e que suas partes (fragmentos) não estão e nem podem ser vistas e estudadas sem a compreensão e aceitação do todo no qual figuram. Claro que não se podem explicar de maneira lógica as relações e inter-relações deste todo e de suas partes e vice-versa. É por isso que se chama pensamento complexo, pois parece não haver uma lógica para essas relações aparentemente sistêmicas. É o que Morin $(5,7)$ denomina a "ordem dentro da desordem" ou a "certeza da incerteza", e é justamente por este motivo que se chama complexidade. Assim, o autor chama a atenção para o conhecimento multidimensional, o que vai contra a fragmentação de disciplinas e o conhecimento extremamente especializado.

A ciência clássica acreditava em um mundo mecânico, em um ser humano mecânico e em uma relação mecânica entre ser humano e o mundo, e que tudo isso poderia ser explicado $(8,10)$. A ciência nova surge como contraponto, explicando que o ser humano não é mecânico, também vive de incertezas e de desordem. O mundo funciona por meio de um conglomerado caótico (11), que a mente humana não pode conceber com exatidão em suas estruturas, pois podem não ser fixas - talvez sejam mutantes, imprevisíveis e autoorganizáveis, ou seja, em um sistema aparentemente caótico, o mundo se autorregula e se auto-organiza $(5,7)$.

Assim, Morin, com sua Teoria da Complexidade, iluminou o debate na construção do PPP da UFPR Litoral e do curso de Fisioterapia em diversos aspectos. Realçou o fato de que o ser humano não é mecânico, mas sim um ser complexo. E embora não seja mecânico, tampouco uma máquina, vem sendo educado como se fosse uma. Ou seja, o professor, detentor do conhecimento, "deposita o conhecimento" no encéfalo do aluno. $\mathrm{O}$ aluno deve absorver esse conhecimento e gravá-lo, semelhante a um computador. Na sequência, em prova, o aluno é cobrado pelo quanto do que foi depositado em seu encéfalo ele foi capaz de memorizar. Se memorizou o bastante, segue adiante em seus estudos, avançando no currículo. Caso contrário, retorna ao estágio inicial de depósito/memorização. Desse modo, a complexidade problematiza esse processo. Sendo o ser humano algo complexo, seu processo de educação também o deve ser. Como mencionado anteriormente, Morin coloca que a complexidade rompe com o conservadorismo, que é um elemento presente no cenário da educação. Assim, é necessário ousar para promover uma educação complexa.

Nessa mesma direção, o PPP da UFPR Litoral também agrega a proposta de Masetto (12) na busca pelo desenvolvimento da aprendizagem dos estudantes, para aperfeiçoar sua capacidade de pensar, de dar 
significado para aquilo que é estudado, de aprimorar a capacidade de construir seu próprio conhecimento. Sem dúvida, essa nova concepção, que enfatiza o processo de aprendizagem, exige uma mudança de atitude docente, em que professor e estudante são coparticipantes do mesmo processo. $\mathrm{O}$ autor conceitua o processo de aprendizagem como um processo de crescimento e desenvolvimento de uma pessoa em sua totalidade, abrangendo minimamente quatro áreas: a do conhecimento, a afetivo-emocional, a de habilidades e a de atitudes.

Jorge Larrosa Bondia (13) é outro autor que fala sobre a importância de que os conteúdos estudados tenham significado para o estudante. Para o autor, essa é condição sine qua non para a construção do conhecimento. Em seu trabalho "Notas sobre a experiência e o saber de experiência", ele comenta sobre a importância de o estudante experienciar/vivenciar o processo de aprendizagem. Tal experiência deve ser algo "que nos passa", "que nos toca", "que nos move" e não algo "que se passa" ou "que se move"3. O autor critica o excesso de informação no mundo contemporâneo, acrescentando que esta informação por si só não se constitui em aprendizagem. O excesso de informação, sem um significado para quem a recebe, não é sinônimo de conhecimento e tampouco de experiência. Com base nessa premissa, foi delineado o eixo FTP. Nesse eixo não caberia, de acordo com o autor, o excesso de informação e de conteúdos, mas sim conteúdos que trouxessem significado para o estudante, que despertassem o interesse em apreender e que realmente faça sentido estudar. Dessa forma, conteúdos tradicionalmente vistos de maneira fragmentada, em disciplinas nos cursos convencionais, são agregados em módulos temáticos que articulam o conhecimento de maneira integrada. E tais módulos são permeados por situações e vivências que permitem ao estudante experienciar, fazendo com que o conhecimento "o passe", "o toque", ou "o mova".

Outro ponto nevrálgico que embasa a experiência da UFPR é a atual crítica às metodologias expositivas de aprendizagem, especialmente no que tange à apreensão de conteúdos pelos discentes (14-17). É um método em que o estudante porta-se passivamente, apenas recebendo os conteúdos "transmitidos" pelo docente. Nesse contexto surgem as metodologias ativas de ensino-aprendizagem, destacando-se os formatos de aprendizagem baseada em problemas e, mais recentemente, a aprendizagem por projetos, abrangendo o paradigma emergente e sua prática pedagógica (14, 18-21).

A estratégia de desenvolvimento de projetos é uma forma complexa de conceber o aprendizado. Ela envolve o estudante, o professor, os recursos disponíveis, inclusive novas tecnologias, e todas as interações que se estabelecerem nesse ambiente, denominado ambiente de aprendizagem. Tal ambiente é criado para promover a interação entre todos os seus atores, propiciando o desenvolvimento da autonomia do estudante e a construção ativa de conhecimentos de distintas áreas do saber, por meio da busca de informações significativas para a compreensão, representação e resolução de uma situação-problema. O planejamento e a execução do projeto de aprendizagem permitem que "se lhes passe" o conhecer, o compreender, o propor e o agir (13).

A pedagogia por projetos fundamenta-se nas ideias piagetianas sobre desenvolvimento e aprendizagem, inter-relacionadas com outros pensadores, dentre os quais se destacam Freire e Vygotsky. Essa nova cultura de aprendizagem torna a escola capaz de: atender às demandas da sociedade; considerar as expectativas, potencialidades e necessidades dos estudantes; criar um espaço onde professores e estudantes tenham autonomia para desenvolver o processo de aprendizagem de forma cooperativa, com trocas recíprocas; desenvolver a habilidade de aprender a aprender, em que cada um pode construir o conhecimento, integrando conteúdos e habilidades de forma transdisciplinar; desenvolver diversas capacidades, muitas das quais preconizadas pelas Diretrizes Curriculares Nacionais (DCN), tais como: trabalho em equipe, tomada de decisões, comunicação, liderança e empreendedorismo $(14,21)$.

A pedagogia por projetos pode contemplar projetos desenvolvidos pela instituição, por docentes ou discentes. No último caso são denominados projetos de aprendizagem (PA). Neles os conteúdos necessários à formação discente emergem de um todo unitário da própria situação em estudo. Sem fragmentação disciplinar,

\footnotetext{
3 Bondia (13), em sua obra original, em espanhol, faz um jogo de palavras de difícil tradução para o português. O autor coloca que a experiência é "o que nos pase". Em português dir-se-ia que a experiência é "o que nos acontece" ou "o que nos passa"; em francês a experiência seria "ce que nous arrive"; em italiano, "quello che nos succede"; em inglês, "that what is happening to us"; em alemão, "was mir passiert".
} 
são direcionados por uma motivação intrínseca: o seu desejo que "o move a desenvolver o seu projeto". Cabe ao docente problematizar, mediar e orientar, provocando a tomada de consciência sobre os conceitos implícitos nos projetos e sua respectiva formalização. Importante mencionar que os PA articulam-se com os outros eixos curriculares, permitindo modificações temáticas nos FTP e ICH, de acordo com demandas da sociedade e dos projetos que cada estudante/turma desenvolve ao longo do curso. Sendo assim, a plasticidade é a principal característica da organização curricular na pedagogia por projetos, abolindo a visão cartesiana reducionista do conhecimento fragmentado. E finalmente, mas não menos importante, é digno considerar que a estratégia de aprendizagem por projetos é capaz de agregar sem dicotomias a tríade ensino-pesquisaextensão na formação do fisioterapeuta.

Outro elemento marcante na estratégia de aprendizagem por projetos, e essencial na relação docente/ discente, discente/discente e discente/docente/comunidade, é a criatividade, que constantemente é exercitada e estimulada nos espaços de aprendizagem. Com isso, busca-se projetar um futuro para a Fisioterapia, somando conhecimento popular e científico, remetendo sempre à história da profissão, seus fundamentos legais e éticos, como preconizam as DCN (22).

Esse alicerce legal, ético e humano é fundamental na execução do Projeto Pedagógico do Curso (PPC) de Fisioterapia da UFPR Litoral, que vislumbra a formação de um profissional fisioterapeuta com perfil diferenciado, considerando o conceito ampliado de saúde, os ciclos da vida humana e os diferentes níveis de complexidade. Assim, o futuro profissional deverá desenvolver habilidades e competências técnicas com características humana, crítica, autônoma e pró-ativa na busca do exercício da cidadania e do profissionalismo responsável, procurando sempre a inovação em saúde para atender às necessidades da sociedade onde atua.

A universidade desempenha um importante papel na construção do conhecimento e na produção de saberes, tornando o indivíduo capaz de resolver problemas e promover mudanças. Por isso, ensino-pesquisa-extensão não podem caracterizar-se por práticas isoladas e com finalidade exclusivamente acadêmica. Esse olhar para a comunidade é essencial para que o profissional, em especial o da Saúde, se sensibilize com questões epidemiológicas, sanitárias, sociais e culturais, as quais permeiam o indivíduo e a comunidade. Dentro dessa perspectiva, o PPP da UFPR Litoral busca de forma inovadora, por meio dos projetos, imbricar ensino-pesquisa-extensão, fazendo do tripé da educação um único pilar norteador do processo de construção do conhecimento. Desde o primeiro ano o estudante é instigado a conhecer, aprofundando os horizontes de sua realidade. A primeira fase, ou primeiro ano do curso é denominado "conhecer e compreender". Essa fase é marcada pela introdução à realidade do litoral, à profissão e ao mundo universitário. O conhecer se faz necessário para que o aluno compreenda a estrutura ao seu redor e valorize seu papel enquanto cidadão e profissional. Esse espaço, presente nas atividades formativas curriculares, permite que o acadêmico entre em contato e problematize de forma precoce questões relativas à região, à profissão ou mesmo ao interesse pessoal sobre determinado assunto. Dessa maneira, o estudante aguça sua curiosidade intelectual, estimula seu senso crítico perante novas linguagens e conhecimentos, progredindo naturalmente para a segunda etapa do curso, chamada "compreender e propor". Nessa nova fase aprofunda os conhecimentos metodológicos e científicos da profissão, propondo estratégias de projetos com base nos subsídios "conhecidos e compreendidos" durante a primeira fase.

Nessa perspectiva, é atribuído ao docente o papel de mediador, tornando-o responsável por auxiliar o acadêmico a estabelecer relação entre os saberes técnicos e sua importância, abrangência e aplicabilidade. Assim, o estudante é capaz de refletir sobre de que forma os FTP (conteúdos das áreas morfofuncional, clínica e psicossocial, por exemplo) se relacionam entre si, bem como de que forma esses conhecimentos se fazem presentes em seu cotidiano e são aplicados em seu projeto.

A aprendizagem é um processo contínuo e inacabado, que depende de fatores intrínsecos e extrínsecos ao indivíduo. Entre os fatores intrínsecos estão a história de vida do sujeito, assim como seus anseios, motivações e limitações, que modificam seu olhar perante a realidade, fazendo com que o seu significado seja repensando. No processo de significação da informação, a troca de experiências entre aluno e professor é inerente à construção do conhecimento. Já entre os fatores extrínsecos encontram-se os fatores ambientais e os acontecimentos do cotidiano, que alimentam a formação de saberes. 
Então, a partir do reconhecimento dos seus anseios pessoais e pela reflexão do seu papel diante de uma realidade, o sujeito se sensibiliza com as questões do outro, identificando demandas sociais. Nesse contexto, o conhecimento técnico o auxilia e o instrumentaliza na busca pela experimentação da prática profissional, ressaltando o seu papel como agente promotor da mudança. E nesse cenário que o estudante adentra a última fase do curso, marcada pela imersão na realidade profissional e denominada "propor e agir". No litoral do Paraná, o trabalho conjunto desenvolvido pela universidade com apoio da comunidade refletese em "propostas e ações" em diversos setores: nos programas de saúde da família, nos centros de educação infantil, em trabalhos com idosos, nas comunidades de ilhas e locais geograficamente isolados do litoral, e até mesmo em assentamento do Movimento Sem Terra (MST) da região, entre tantos outros.

Assim, os projetos, seguindo as três fases do curso, servem como recursos para que o estudante se torne um sujeito autônomo e consciente do seu papel enquanto profissional de saúde (e não da doença). Quando a realidade tem sentido na prática pedagógica, integra um todo em que acadêmico, professor, instituição e comunidade tornam-se corresponsáveis pela mudança do panorama local. Assim, nessa perspectiva de coletividade, atores sociais e instituição podem ser capazes de atuar de forma plena, estimulando a cidadania, promovendo a saúde e fomentando o desenvolvimento sustentável de uma região.

\section{Considerações finais}

O curso de Fisioterapia da UFPR Litoral vem sendo implantado e implementado, buscando a integração das fases do seu PPP, perpassando os três espaços curriculares de aprendizagem: FTP, ICH e PA. Esses espaços têm objetivos que contemplam em grande parte as DCN e muitos dos direcionamentos sugeridos pelos fóruns da ABENFISIO.

Atentos ao fato de que "a Fisioterapia deve atender às necessidades sócio-educacionais da comunidade onde está presente" (23), entendemos que a construção inovadora e dinâmica do projeto do curso se reflete em ações de efeitos imediatos, progressivos e permanentes. Essas podem contribuir tanto para o desenvolvimento da região onde está o curso, quanto para a atualização da profissão de fisioterapia, atendendo a novas realidades e campos de atuação.

A universidade tem deveres para com a universalidade e a pluralidade de princípios e objetivos. Assim, para uma transformação completa é natural que algumas crises ocorram (24). Ao longo da trajetória da construção do Curso de Fisioterapia da UFPR Litoral, as (muitas) crises foram transformadas em desafios, a serem vencidos numa abordagem coletiva na câmara do curso. Dentre tantas, talvez algumas tenham sido mais significativas, e merecem ser elencadas: a formação no modelo tradicional dos docentes, como paradoxo para uma atuação inovadora na docência; os próprios estudantes que traziam em suas histórias de vida uma formação positivista e cartesiana e que se deparavam como um novo paradigma educacional (complexo), que exigia pró-atividade e corresponsabilidade; e as diferentes metodologias de ensinagem, que deveriam ser criativas e com novo formato de atividades formativas; o processo de avaliação, não simplesmente buscando avaliar o estudante imbuído do desejo de "lançar notas", aprovar ou reprovar, mas tentando avaliá-lo como um todo.

Não resta dúvida de que tal construção passa pela mudança de rumos nas propostas de formação dos sujeitos. A formação de pessoas acontece em diversos espaços e contextos, que embora tenham conteúdos diferenciados e, por vezes, contraditórios, complementam-se. Na sociedade moderna, a universidade tem a primazia do processo de formação de indivíduos no sentido da escolarização e instrução, ou melhor, de aquisição do conhecimento sistematizado e contato com o saber científico. E, logicamente, não deve se restringir a isso. Deve preocupar-se com a ampla formação do sujeito, extrapolando o simples domínio de habilidades específicas da profissão. É necessário, pois, formar o sujeito integral, na perspectiva colocada por Pistrak (25) e Marx (26), em que a formação do "novo ser humano" subentende uma mudança de hábitos e a conformação de uma identidade coletiva cunhada na dimensão cultural, dentro da qual a linguagem dos sujeitos é fator preponderante.

Evidentemente, essa nova forma pedagógica de agir exige que se privilegiem a contradição, a dúvida, o questionamento, a problematização; que se valorizem a diversidade, a pluralidade e a divergência; que se 
interroguem as certezas e as incertezas, despojando os conteúdos de sua forma naturalizada, pronta e imutável. A organização do trabalho pedagógico, explicitada no PPP, deve assegurar que cada conteúdo seja "analisado, compreendido e apreendido dentro de uma totalidade dinâmica", seguindo uma metodologia dialética. Tal metodologia propõe "caminhar da realidade social para a especificidade da sala de aula, e desta para a totalidade social novamente" (27), de forma transformada. Em outras palavras, o trabalho pedagógico não poderá prescindir da análise crítica da realidade atual, da interdisciplinaridade e da relação teoria-prática. $\mathrm{Na}$ estreita articulação teoria-prática se constitui, portanto, a práxis pedagógica, como atividade transformadora.

Assim, tanto o projeto político da instituição quanto o do Curso de Fisioterapia devem estar em sintonia com o processo dinâmico de construção dos saberes e das necessidades socioeconômicas, educacionais, culturais e ambientais da região onde está implantado. O mesmo deve ocorrer no processo de ensinoaprendizagem, perpassando pelo conhecimento existente e permitindo a construção de novos conhecimentos, com ações inovadoras e responsáveis, relacionadas com a sociedade, em sua tríade de desenvolvimento: ser humano, ambiente e tarefas.

E como finalização deste artigo (mas não do debate), deixa-se o seguinte pensamento do sábio educador Paulo Freire (27), que diz que "o ser humano é um ser cultural, histórico, inacabado e consciente do inacabamento". E assim somos todos e todas: atores e atrizes sociais inacabados, no convívio e na construção coletiva; numa construção inacabada, seja no desenvolvimento de metodologias criativas, seja no desenvolvimento de um Projeto Político-Pedagógico (inacabado)... E conscientes de todo esse inacabamento.

\section{Referências}

1. Maturana HR, Varela FJ. A árvore do conhecimento: as bases biológicas da compreensão humana. Mariotti H, Diskin L, Tradutores. São Paulo: Palas Athena; 2001.

2. Morin E. A cabeça bem-feita: repensar a reforma, reformar o pensamento. Jacobina E, Tradutor. 4a ed. Rio de Janeiro: Bertrand Brasil; 2001.

3. Morin E, Le Moigne JL. A inteligência da complexidade. Falci LM, Tradutor. São Paulo: Peirópolis; 2000.

4. Morin E. Ciência com consciência. Alexandre MD, Dória MAS, Tradutores. 8a ed. Rio de Janeiro: Bertrand Brasil; 2005.

5. Morin E. Os sete saberes necessários à educação do futuro. São Paulo: Cortez; 1999.

6. Morin E. Educação e complexidade: os sete saberes e outros ensaios. São Paulo: Cortez; 2002.

7. Morin E. A ciência com consciência. 6a ed. Rio de Janeiro: Bertrand Brasil; 2002.

8. Moles AA. A criação científica. São Paulo: Perspectiva; 1971.

9. Von Bertalanffy L. Teoria geral dos sistemas. 3a ed. Rio de Janeiro: Vozes; 1977.

10. Price DS. A ciência desde a Babilônia. Belo Horizonte: Itatiaia; 1976.

11. Prigogine I. As leis do caos. São Paulo: UNESP; 2002.

12. Masetto MT. Competência pedagógica do professor universitário. São Paulo: Summus; 2003.

13. Bondia JL. Notas sobre a experiência e o saber de experiência. Rev Bras Educação. 2002;19:20-8.

14. Araújo UF. Temas transversais e a estratégia de projetos. São Paulo: Moderna; 2003.

15. Anastasiou LGC, Alves LP. (Org.). Processos de ensinagem na universidade. Joinville: Ed. da Univille; 2003.

16. Vasconcellos CS. Construção do conhecimento em sala de aula. 10a ed. São Paulo: Libertad; 2000.

17. Cunha MI. Sala de aula: espaço de inovações e formação docente. In: Enricone D, Grillo M. (Org.). Educação superior: vivências e visão de futuro. Porto Alegre: EDIPUCRS; 2005. 
18. Behrens MA. O paradigma emergente e a prática pedagógica. Petrópolis: Vozes; 2005.

19. Finger AP, Pinto EP, Luck H. Educação: caminhos e perspectivas. Curitiba: Champagnat; 1996.

20. Saarinen-Rahiika H, Binkley JM. Problem-based learning in physical therapy: a review of the literature and overview of the McMAster University experience. Physical Therapy. 1998;78(2):195-212.

21. Almeida MEB. Projeto: uma nova cultura de aprendizagem. 1999. [acesso 25 set. 2009]. Disponível em: http:// www.educacaopublica.rj.gov.br/biblioteca/educacao/0030.html

22. Brasil. Resolução CNE/CES n. 4, 19 out. 2002. Institui Diretrizes Curriculares Nacionais do Curso de Graduação em Fisioterapia. [acesso 25 set. 2009]. Disponível em: http://portal.mec.gov.br/cne/arquivos/pdf/CES042002.pdf

23. Israel VL. Caracterização da atuação profissional de um grupo de fisioterapeutas da cidade de Curitiba. [dissertação]. São Carlos: Universidade Federal de São Carlos; 1993.

24. Cavallet VJ. Os desafios da educação no ensino superior e a avaliação da aprendizagem. In: Avaliação da aprendizagem no ensino superior PUCPR, 27 maio 1999. Curitiba. 1999.

25. Pistrak MM. Fundamentos da escola do trabalho. 2a ed. São Paulo: Expressão Popular; 2002.

26. Marx K. Crítica da educação e do ensino. Lisboa: Moraes; 1978.

27. Freire P. Pedagogia da autonomia: saberes necessários à prática educativa. São Paulo: Paz e Terra; 1996.

Recebido: 14/10/2009

Received: 10/14/2009

Aprovado: 22/02/2010

Approved: 02/22/2010

Revisado: 13/05/2010

Reviewed: 05/13/2010 